\title{
COlONIALIDADE E ASSIMETRIA NOS CONTEXTOS SUL-AMERICANOS DA LÍNGUA PORTUGUESA
}

COLONIALITY AND ASYMMETRY IN THE PORTUGUESESPEAKING SOUTH AMERICAN CONTEXTS

\author{
Alexandre Montaury \\ ORCID 0000-0003-0590-9910
}

Pontifícia Universidade Católica do Rio de Janeiro Rio de Janeiro, RJ, Brasil

\begin{abstract}
Resumo
O presente texto tem como objetivo central desenvolver uma reflexão sobre condiçôes preliminares de análise do que poderiam algumas especificidades no desenvolvimento das políticas coloniais portuguesas, presentes na experiência mais antiga empreendida no Brasil e, mais recentemente, até o último quarto do século XX, em países africanos. Inúmeras obras de ficção modernas e contemporâneas focalizaram, direta ou indiretamente, as derivas de uma mentalidade colonial no interior das ex-colônias portuguesas. A memória desta experiência, que implica regimes tensos de coabitação epistêmica, têm sido identificada por parte da crítica como um dos traços estruturantes da contemporaneidade. $\mathrm{O}$ artigo pretende identificar algumas respostas que o campo literário tem procurado oferecer aos legados e às heranças desta experiência, a partir de premissas teórico-metodológicas disponíveis nos campos de estudos pós e de-coloniais.
\end{abstract}

Palavras-chave: Literatura, Colonialidade, Política, ficção moderna e contemporânea.

\section{Résumé}

Ce texte a pour objectif de développer une réflexion sur les conditions préliminaires d'analyse de ce que pourraient être certaines spécificités dans le développement des politiques coloniales portugaises, présentes dans la plus ancienne expérience menée au Brésil et, plus récemment, jusqu'au dernier quart du XXe siècle, dans des pays africains De nombreuses œuvres de fiction modernes et contemporaines se sont concentrées, directement ou indirectement, sur la dérive d'une

\section{Abstract}

This paper aims to prompt a reflection on preliminary conditions of analysis of some specificities in the development of Portuguese colonial policies, present in the oldest experience undertaken in Brazil and, more recently, in the last quarter of the twentieth century, in African countries. Numerous modern and contemporary works of fiction have focused, directly or indirectly, on the drift of a colonial mentality within the former Portuguese colonies. The memory of this experience, which implies tense 
mentalité coloniale au sein des anciennes colonies portugaises. Le souvenir de cette expérience, qui implique des régimes tendus de cohabitation épistémique, a été identifié par les critiques comme l'un des traits structurants de l'époque contemporaine. L'article vise à identifier certaines des réponses que le domaine littéraire a tenté d'apporter aux héritages de cette expérience, à partir des prémisses théoriques et méthodologiques disponibles dans les domaines d'étude post et décolonial.

Mots-clés : Littérature, colonialité, politique, fiction moderne et contemporaine regimes of epistemic cohabitation, has been identified by critics as one of the structuring traits of contemporary times. This article intends to identify the answers that the literary field has tried to offer to the legacy and heritage resulting from this experience, based on theoretical and methodological premises available in the post and de-colonial fields of study.

Keywords: Literature, Coloniality, Politics, Modern and Contemporary Fiction

Estamos todos, hoje, na decorrência de uma colonização que foi dando sumiço àqueles que da maneira como viviam não tinham maneira de resistir, servimo-nos da mesma língua oficial, invocamos lusofonias de hoje que já foram lusotropicalismos antes, somos todos do hemisfério sul, com a cor geopolítica comum que isso comporta, e temos negócios correntes, estamos vivendo tempos comuns e tempos diversos do mesmo processo universal, global (CARVALHO, 2006, p. 251).

A epígrafe que abre este texto foi selecionada por condensar tópicos que, em linhas gerais, pavimentam o horizonte de interesses em que se insere o plano de estudos que tenho empreendido. Foi extraída do livro Desmedida - Luanda, São Paulo, São Francisco e volta: crônicas do Brasil', do escritor angolano Ruy Duarte de Carvalho, que operou um singular esforço analítico-narrativo dos processos históricos, culturais e políticos que marcaram duas sociedades - a angolana e a brasileira -, formadas no interior da tradição colonial portuguesa e inscritas, em temporalidades heterogêneas, no contexto mais amplo da modernidade ocidental. A premissa fundamental do seu texto é a de que esta condição de fundo, forjada no binômio colonialidade-modernidade, deu forma a um campo cultural específico, inscrito na evidência de uma experiência histórica comum - a colonização portuguesa -, que, na contemporaneidade, revelaria ainda "continuidades e contiguidades" (CARVALHO, 2006, p. 19), ou seja, derivações simbólicas das visões coloniais de mundo.

1 Carvalho, Ruy Duarte de. Desmedida: Luanda, São Paulo, São Francisco e volta. Lisboa: Cotovia, 2006. 
Para o arco argumentativo que buscarei descrever, é fundamental considerar que em todos os espaços da língua portuguesa, o binômio colonialidade-modernidade produziu linhas divisórias e "abissais", baseadas em clivagens epistemológicas ${ }^{3}$. Ao hierarquizar sistemas culturais, esse binômio induziu a sedimentação de paradigmas que inferiorizaram as formas de vida não integradas aos modelos europeus de civilização. Em outras palavras, as formas hegemônicas de vida, orientadas por paradigmas eurocentrados e legitimadas por formas de produção e de conhecimento consideradas superiores, destacaram-se diante de formas tradicionais de vida, baseadas em experiências e práticas não-europeias. As racionalidades gestadas em mundividências do sul, baseadas em cosmovisóes e universos simbólicos próprios, foram sistematicamente identificadas como culturas do atraso a serem corrigidas nos processos civilizatórios da modernidade colonial.

Em A sociedade contra o Estado (1974), o antropólogo francês Pierre Clastres identificou algumas das perplexidades que marcaram o encontro entre o colonizador europeu e as sociedades tradicionais sul-americanas. Entre elas, chama a atenção que a percepção então vigente acerca das sociedades primitivas pressupunha a noção de uma temporalidade específica; estariam essas à margem da história universal, como "sobrevivências anacrônicas de uma fase distante e, em todos os lugares, há muito ultrapassada?” (CLASTRES, 1974, p. 35)

Reconhece-se aqui a outra face do etnocentrismo, a convicção complementar de que a história tem um sentido único, de que toda sociedade está condenada a inscrever-se nessa história e a percorrer as suas etapas que, a partir da selvageria, conduzem à civilizaçãó ${ }^{4}$. (CLASTRES, 1974, p. 35)

O projeto de pesquisa que tenho desenvolvido desde 2014 é um dos subsídios relevantes para a elaboração deste ensaio, pois, em suas diferentes etapas, temos buscado empreender esforços suplementares de depuração teórico-metodológica da pesquisa, buscando, simultaneamente, um permanente alargamento do corpus literário de pesquisas anteriores. A premissa central de que se parte é a de que as visóes coloniais de mundo, nas palavras do sociólogo português Boaventura de Sousa Santos, "permanecem constitutivas das relaçôes políticas e culturais excludentes mantidas no sistema mundial

2 Expressão empregada por Boaventura de Sousa Santos em seu artigo "Para além do pensamento abissal: das linhas globais a uma ecologia dos saberes". Novos estudos, CEBRAP, número 70, São Paulo, novembro de 2007.

3 Em linhas gerais, neste breve texto os conceitos de episteme e epistemologia compreendem o conjunto de fundamentos que determinam formas específicas de conhecimento, de produção de saberes e de visóes específicas de mundo.

4 Clastres, Pierre. La societé contre l'État: Recherches d'anthropologie politique Paris: Editions Minuit, 1974. 
contemporâneo" (SANTOS, 2007, p. 71). Em outras palavras, pretende-se considerar o pressuposto de que o fim do colonialismo político náo representou o fim de práticas simbólicas estreitamente identificadas com o colonialismo. Segundo o pesquisador peruano Aníbal Quijano, "a globalização em curso é, antes de tudo, a culminação de um processo que começou com a constituição da América e do capitalismo colonial/moderno e eurocentrado como um novo padráo de poder mundial" (QUIJANO, 2005, p. 117).

A expansão ocidental e a sua principal condição de possibilidade, o colonialismo político, foram além de um empreendimento administrativo criado para assegurar a transferência de renda das colônias para a metrópole e fomentar, assim, o desenvolvimento industrial europeu. A produção de uma assimetria de fundo, estruturante das relaçóes entre metrópole e colônia, justificava a transferência - em sentido inverso, para espaços "incultos", aparentemente condenados ao déficit de civilização e ao "estado de natureza" de discursos de matriz europeia dotados de uma visão moderna e supostamente superior de mundo. Baseada numa inculcação epistemológica na qual o campo literário desempenha um papel determinante, as exigências da modernidade europeia impuseram o transplante de formas culturais hegemônicas para os espaços coloniais, moldando, em particular, aquelas que, no escopo deste texto, se situam nos continentes sul-americano e africano.

As transiçôes políticas pautadas pelo uso público da razão foram parcialmente assimiladas em Portugal e condicionadas por alguma defasagem cultural e política em relação ao centro da Europa. Ao mesmo tempo, os corpos políticos mantidos sob a colonização portuguesa, radicalmente fragmentados, assimilavam epistemes europeias impostas ao abrigo de eficientes engrenagens discursivas, na órbita de um sentido metafísico e identitário da comunidade. No estágio de desenvolvimento da pesquisa atual, é possível afirmar que a minuciosa análise de dispositivos institucionais ${ }^{5}$ portugueses permite conhecer a inoculação compulsória das noçóes clássicas de estado, de justiça e de bem comum em contextos comunitários fraturados e desiguais. A partir do pressuposto de que o campo literário (a produçáo e a crítica) respondeu sistematicamente às marcas de uma desigualdade de fundo, tenho buscado analisar respostas formuladas no interior do corpus literário selecionado para a pesquisa, ao quadro de desnivelamento nas almas e nos corpos de "além-mar", expostos a tradiçóes sociais violentas e forjados em contextos de opressão colonial. Para oferecer alguns exemplos, citaria o romance $A$ selva, do escritor

5 Para oferecer alguns exemplos, é possível citar a Constituiçăo Portuguesa de 1931, o "Acto Colonial, de 1930", o "Estatuto dos Indígenas Portugueses das Províncias da Guiné, Angola e Moçambique", de 1961, os decretos que estabelecem a Assimilação Cultural, a criaçáo de Prêmios literários coloniais pela Agência Geral das Colônias, entre muitos outros dispositivos discursivos que trataram de definir um rigoroso controle que evitasse "a corrupçáo dos costumes". 
português Ferreira de Castro, publicado em 1930, e Desmedida: Luanda, São Paulo, São Francisco e volta, do escritor luso-angolano Ruy Duarte de Carvalho, publicado em 2006, para apenas afirmar que as respostas literárias aos diferentes quadros de assimetrias, formados na sequência de uma brutal experiência colonial, não é de hoje. Esses são apenas alguns exemplos de narrativas que inscrevem na ordem do visível a singular coabitação de formas minoritárias de vida com a lógica colonial.

Nos limiares culturais da língua portuguesa, essas interaçóes, materializadas como sistemas heterogêneos de produção da vida, mobilizaram conjuntos de imagens e de objetivaçôes que instruíram a formação de literaturas nacionais. Nelas, o acentuado contraste entre a formação de comunidades integradas à ordem moderna colonial e a formação de imunidades, fraturadas pela subalternidade, produziu um quadro visível, marcado por profundas diferenças, estruturantes de uma parte importante da produção literária como imaginação "epistêmica".

Neste sentido, como resultado parcial de um projeto de pesquisa mais amplo, busca-se uma sistematização teórico-metodológica preliminar das especificidades coloniais, anticoloniais, pós-coloniais e de-coloniais, tal como se materializam no universo cultural da língua portuguesa, de modo a contribuir com os estudos comparativos desenvolvidos neste campo de investigaçáo. A partir dos sinais ${ }^{6}$ emitidos a partir de 1930 nos campos literários da língua portuguesa serão examinadas formas de "continuidade e de contiguidade" das experiências da comunidade e da imunidade.

\section{Epistemologias de fronteira e o imaginário das ausências}

Para uma breve análise, proponho relembrarmos as miríades de textos produzidos no século XX que buscaram privilegiar ângulos alternativos e significativos que, uma vez inscritos no campo literário, também permitiram iluminar a interpretação de fatos históricos relevantes, em diferentes perspectivas.

Esses prismas alternativos emergem do que consideramos, com Boaventura de Sousa Santos, o "imaginário das ausências", radicado no esquecimento compulsório do lugar do outro, ou, para ainda citar Michel Foucault, das "heterotopias de desvio" . Os povos da floresta, presentes nas obras de Antonio Callado, Milton Hatoum ou Bernardo Carvalho, assim

\footnotetext{
6 Ginzburg, Carlo. Mitos, emblemas e sinais. Trad.: Federico Carom São Paulo, Cia das Letras, 1990. Neste livro, Carlo Ginzburg propóe o paradigma indiciário como categoria de análise. Trata-se de um conjunto de princípios e de procedimentos que contêm a proposta de um método centrado no detalhe, nos dados marginais, nos resíduos tomados enquanto pistas, indícios, sinais, vestígios ou sintomas.

7 Foucault, Michel. “Outros espaços”. In: Ditos e escritos. Rio de Janeiro: Forense Universitária, 2000. v. 3, p.115.
} 
como os pastores nômades do Kuvale, em Angola, decisivos em toda a obra de Ruy Duarte de Carvalho, ou mesmo os camponeses de Pepetela, mais do que formas minoritárias de vida, identificadas no interior das culturas de língua portuguesa, constituem paisagens humanas tradicionais, que foram capazes de sobreviver aos vetos à diferença e a "direitos epistêmicos", à margem das institucionalidades oficiais. Não se trata de uma salvação; trata-se, antes, de recomeços, de rexistência, no sentido utilizado pelo antropólogo Eduardo Viveiros de Castro.

Associados aos damnés, na terminologia de Frantz Fanon, esses e inúmeros grupos sociais - que, em sentido ainda mais abrangente, ainda poderiam compreender os "capitáes de areia", de Jorge Amado, ou os sertanejos de Guimarães Rosa, os seringueiros de Ferreira de Castro, os "plantadores de arroz do Alentejo" do escritor neorrealista português Alves Redol. São miríades de personagens e narrativas que apresentam uma instrução fundamental acerca dos contextos da língua portuguesa: eles se formam a partir de uma coabitação epistêmica estruturante, que mescla paradigmas europeus, visões ameríndias e africanas de mundo. $\mathrm{O}$ argumento central deste texto baseia-se na premissa de que a dimensão policêntrica de um mundo em que "muitos mundos podem coexistir" (MIGNOLO, 2008, p. 296) e afirma-se em inúmeros textos literários produzidos em língua portuguesa a partir dos anos 1930. Mesmo quando surgem no agenciamento das racionalidades hegemônicas, isto é, mesmo quando ativadas como objeto exótico, as imagens e as práticas ficcionais podem desocultar formas de vida e de racionalidade marcadas, na modernidade ocidental, por uma subalternidade epistêmica construída lentamente, ao longo dos séculos. Para o pesquisador argentino, Walter Mignolo, em sua defesa da opçáo descolonial, esta clivagem produziu o apagamento das formas afro-escravizadas de vida, o que também toca o emprego violento da força indígena de trabalho na formação de uma economia capitalista através da expansão imperial do ocidente. Segundo o paradigma hegemônico, trata-se de tornar invisível a

perspectiva da maioria das pessoas do planeta cujas vidas foram declaradas dispensáveis, cuja dignidade foi humilhada, cujos corpos foram usados como força de trabalho [...]. Essa é a opção descolonial que alimenta o pensamento descolonial ao imaginar um mundo no qual muitos mundos podem coexistir (MIGNOLO, 2008, p. 296).

Neste sentido, torna-se fundamental identificar e analisar a formação de epistemologias de fronteira, a partir da noção de uma consciência mestiça, vivida e experimentada na consciência de um universo cultural marcado pela complexidade epistemológica. Para citar o crítico Antonio Cândido, a 
existência de uma "sociedade parcial dotada de cultura parcial" (CÂNDIDO, 1964, p. 8), híbrida, decorrente de pertenças compartilhadas e nascidas da coabitação entre valores tradicionais e valores urbanos permite considerar os estudos pós-coloniais, e de-coloniais, para avançar na detecção de uma zona de mesclagens, onde as práticas simbólicas de grupos minoritários são parcialmente apropriadas pelas culturas comunitárias. $\mathrm{O}$ reconhecimento efetivo da sobrevivência de grupos culturais, especialmente de matriz africana ou ameríndia, permitirá avançar na perspectiva das formas de inserção e de interação entre diferentes sistemas culturais, de maneira a relativizar a dimensão endógena de suas formaçôes.

Comunidade e colonialidade:

Nos campos culturais da língua portuguesa, a afirmação de uma unidade linguística e de uma comunhão de experiências históricas, baseadas em regimes de trocas e apropriaçóes, ajudou a definir paisagens comuns, ao mesmo tempo em que sedimentou ou distorceu escalas de valores eurocentrados em contextos não-europeus. A partir dos anos 1940, a produção literária, nas variantes africanas da língua portuguesa, pôs em cena uma sistemática interrogação dos processos de assimilação cultural, de punições violentas, de imposiçóes coloniais, aprofundando uma sensibilidade anticolonial que foi radicalizada nas décadas posteriores. Neste aspecto, é inevitável referir aos escritores angolanos que, como intelectuais, operaram no campo ficcional uma estratégia de barragem às práticas e às linguagens do comum, tal como eram definidas segundo a agenda do colonialismo português. Duas décadas depois das independências, foram formalizados os fundamentos que estruturam a constituição jurídica da CPLP (Comunidade dos Países de Língua Portuguesa), em 1996; a assinatura do Acordo Ortográfico, vigente desde janeiro de 2012, com o propósito de reforçar sentidos de comunidade em contextos englobantes e heterogêneos e, finalmente, as exigências mais recentes, associadas às leis 10.639 (2003) e 11.645 (2008), que passam a exigir a obrigatoriedade da inclusão do estudo da história e da cultura afro-brasileira e indígena nos currículos oficiais das redes nacionais de ensino.

Um dos pilares de sustentação das políticas coloniais portuguesas foi o princípio da unidade comunitária, que corresponde ao projeto de constituição de um comunitarismo identitário, metafísico e transcendente, baseado em uma "mútua pertença" que se espalhava "do Minho ao Timor". Nos espaços africanos subjugados pela lógica colonial portuguesa, a opressão dos indivíduos era dissimulada por políticas oficiais que, numa linguagem jurídica e institucional, e através de campanhas publicitárias, ofereciam a assimilação cultural como uma via de acesso ao pertencimento comunitário. 
Revestido por um discurso de conciliação com as práticas coloniais, nos termos do lusotropicalismo brasileiro $(1940)^{8}$, o colonialismo português ativou, nos espaços africanos, uma retórica eficiente que exaltava os brandos costumes de uma nação pluricultural, plurirracial e pluricontinental. Uma coesa engrenagem discursiva tratava de celebrar uma dádiva prévia, um dom que a democracia racial e a civilização mestiça portuguesa prometiam nos espaços ultramarinos: a integração harmônica entre as formas minoritárias de vida e as expectativas de uma modernidade portuguesa. Os administradores dos postos coloniais em Angola e em Moçambique eram responsáveis por atestar que as práticas simbólicas e culturais de um indivíduo candidato à assimilação eram "compatíveis com a moral e com os ditames da humanidade"; em outras palavras, um indivíduo até podia se tornar um assimilado se fosse capaz de renunciar à sua tradição cultural própria. Entretanto, a adoção dos modos de vida europeus não assegurava direitos iguais a todos. $\mathrm{O}$ uso da língua portuguesa, os modos de viver e de vestir, entre outros, eram determinantes para a definição dos lugares sociais a serem ocupados pelos "assimilados"10. Tratava-se de promover, nas sociedades africanas, a inoculação compulsória de valores forjados no regime colonial europeu e, ao mesmo tempo, de hierarquizar racionalidades distintas, apagando as práticas tradicionais identificadas com o atraso.

Neste contexto, a literatura moderna, em todas as suas variantes linguísticas, atuou ora na fabricação de uma atmosfera propensa à ideia de comunidade, ora na insurgência contra esta hegemonia comunitária. Em síntese, na sua tradição mais ou menos canônica, a produção literária funcionou, de um lado, como usina de senso comum, integrada às racionalidades hegemônicas, e, de outro, produziu profundas imunidades ao centro irradiador das visóes modernas de mundo. Neste campo de negaçóes e negociaçóes, a noção teórica de comunidade permitiu a identificação da falência dos projetos de comunidades identitárias que enformaram grande parte da experiência da modernidade colonial, norteando, ao mesmo tempo, as derivas simbólicas e culturais que permanecem presentes no contemporâneo.

8 Em Casa-grande \& senzala (1933); O mundo que o português criou (1940) e "Uma cultura moderna: a luso-tropical", entre outros textos, o sociólogo brasileiro Gilberto Freyre desenvolveu a teoria lusotropicalista, para, de modo geral, tratar da especificidade do colonialismo português, modalizando a violência das práticas coloniais portuguesas no Brasil.

9 Cf. Artigo 22․ Do Acto Colonial de 1930. Consulta em 22 de junho de 2017. Disponível em: http:// www.parlamento.pt/Parlamento/Documents/acto_colonial.pdf

10 Ver o documentário. "O colonialismo português em África: multiculturalismo", produzido pela Rede de Televisão Portuguesa (RTP). Consulta em 18 de junho de 2019. Consulta em 29 de junho de 2019. Disponível em https://www.youtube.com/watch?v=6pOItIQYBO4. 
Retomo, apenas à guisa de conclusão, duas objetivações literárias já citadas para lembrar a leitura que os escritores Ferreira de Castro e Ruy Duarte de Carvalho propóem para a constituição assimétrica do Brasil, em coerência com o seu passado colonial.

No romance de Ferreira de Castro, a paisagem funciona como elemento central que desencadeia um conjunto de percepçóes acerca da memória colonial. Nos textos que introduzem o romance, o escritor afirma claramente o seu projeto de reconstituir no terreno da ficção a experiência de sua juventude, em parte vivida na região amazônica, no coração de uma "selva misteriosa e implacável" (FERREIRA DE CASTRO, 1982, p. 15). O autor propóe entregar ao leitor uma espécie de testemunho, em primeira pessoa, "pelo muito que nela sofri" (FERREIRA DE CASTRO, 1982, p. 15), e, com isto, cerca o texto de referencialidades que, logo a abrir o texto, conferem tangibilidade e verossimilhança aos percursos inscritos na estrutura narrativa.

No decorrer do romance, vemos o personagem Alberto percorrer as estradas líquidas da Amazônia até se fixar no seringal Paraíso, localizado, nas primeiras décadas do século XX, em uma das margens do rio Madeira. Por intermédio do tio e de um encarregado do seringal, o personagem, diante de um quadro de profunda escassez de trabalho na região de Belém do Pará, vê-se aceito para ingressar no sistema produtivo da borracha sem ter noção da especificidade de sua inserção. Assim, sem saber bem o que esperar deste trabalho, aceita embarcar, a bordo do Justo Chermont em direção ao seringal e, com isto, se desloca para o interior de uma das mais "densas solidóes do mundo" (FERREIRA DE CASTRO, 1982, p. 15).

$\mathrm{Na}$ experiência concreta da paisagem, as imagens idílicas, literárias, associadas ao mito do paraíso terreal, que compreende a grandeza e a riqueza do novo mundo, adquirem maior densidade e são radicalmente transfiguradas pelo olhar de Alberto. Em inúmeros momentos na narrativa, a viagem anterior dos descobrimentos, assentada nas promessas de expansão da fé e do império, se torna uma "quimera", assim como o táo celebrado exotismo, agora transfigurado em "espectro de pesadelo":

Evocado dali, Portugal era uma quimera, não existia talvez. Pequeno e lá longe, os que o levavam na memória náo estavam certos se viviam em realidade ou se sonhavam com as narraçóes dos que tinham voltado das descobertas. [...] Eles seriam, porventura, uma alucinação sobrevivente de alguém que morrera pensando em fábulas bíblicas, em mundos pré-históricos, e, quando menos o esperassem, desvanecer-se-iam totalmente, como espectros de pesadelo. Só o perigo, mais temido do que em outra parte, por usar máscaras desconhecidas, os reconduzia à realidade, humanizando-os ante eles próprios (FERREIRA DE CASTRO, 1982, p. 47). 
Ao mesmo tempo em que "o perigo [...] os reconduzia à realidade, humanizando-os ante eles próprios”, a paisagem passa a remeter para os resíduos e os rastros deixados na selva amazônica pelos colonizadores portugueses. Sob os olhos de Alberto, a toponímia aproximava as cidades brasileiras - Santarém, Alenquer, Óbidos, Borba e Faro - e as cidades portuguesas. Contudo, esta familiaridade insinuada ao longo do percurso e "a subida, quinze dias bem puxados de Belém ao Paraíso" (FERREIRA DE CASTRO, 1982, p. 57), já não causa estranhamento pela desproporção das escalas dimensionais; mas, antes, converte-se num estranhamento mais profundo, umas vez que as cidades brasileiras, apesar de guardarem os topônimos europeus, em nada se pareciam com cidades portuguesas:

Alberto surpreendia-se ante a prodigalidade com que os homens do mando distribuíam categorias: qualquer daquelas cidades, embora simpáticas na sua modéstia, não igualava sequer uma vila da Europa. As ruas estavam forradas de capim e não era difícil contar, por maioria, as casas cobertas de folhas de palmeira. "Cidade por quê?". Erro grosseiro dos colonizadores portugueses [...] (FERREIRA DE CASTRO, 1982, p. 67).

Neste ponto, parece possível perceber que o texto de Ferreira de Castro não apenas descortina a paisagem amazônica, mas, sobretudo, oferece a visão de mundo do observador. $\mathrm{O}$ assombro que assalta o personagem - e também o narrador - surge nos pontos centrais da narrativa para revelar os valores e os pressupostos cognitivos de um jovem monarquista português, ao contato de uma realidade inteiramente diversa da sua, dotada de racionalidades próprias e de uma cosmovisão alternativa. A impossibilidade de o personagem Alberto ler a complexidade daquela paisagem, ao mesmo tempo em que nela é inserido, parece ser uma das linhas de força que sustentam a narrativa.

É também de uma viagem que trata o livro Desmedida: Luanda, São Paulo, São Francisco e volta, de Ruy Duarte de Carvalho. Neste texto, chama a atenção que, logo nas primeiras páginas do livro, a paisagem seja a de uma fazenda de café localizada no interior paulista, onde o narrador ironicamente se coloca em diálogo com "duas senhoras paulistanas, sentado à mesa delas numa soberba fazenda de café do interior paulista..." (CARVALHO, 2006, p. 18) para associar, de forma sutil, a associação entre a elite cafeeira paulista e os modernistas dos anos de 1920, através da figura de Blaise Cendrars. $\mathrm{Na}$ narração do livro, o escritor é caracterizado como "poeta amputado pela Primeira Guerra Mundial e aventureiro, brilhante e de cigarro, sempre, no canto esquerdo da boca". Na imaginação do narrador estaria a jantar em uma sala colonial, "táo extensa e por certo táo antiga como esta, porém numa fazenda entáo praticamente abandonada pela proprietária, ausente durante mais de duas décadas, na França” (CARVALHO, 2006, p. 28). 
a sala muito extensa e iluminada, de pé-direito altíssimo e de um arranjo que restaurava uma construção por certo muito antiga até, mas muito ao gosto da arquitetura e da decoração restauratórias de agora. [...] e à volta havia mulheres a servi-los, negras e mulatas, algumas nascidas ainda no tempo da escravatura. Porque tudo isso se passava nos anos 20 do século passado, depois de uma viagem transatlântica que tinham feito juntos, com início em Bolonha e apontada ao porto cafeeiro de Santos (CARVALHO, 2006, p. 28).

No século XX, o neorrealismo português e o regionalismo brasileiro desempenharam um papel decisivo nas demarcaçóes de uma condição comum. Inúmeros escritores portugueses, brasileiros, angolanos e moçambicanos operaram, no campo da ficção, um esforço de desocultação das práticas culturais e simbólicas solapadas pelas forças do poder hegemônico. No período, o campo literário assumiu grande protagonismo no combate travado pelas instâncias do imaginário. Neste ponto, é claro que a prática literária desempenhou um papel relevante e os escritores, poetas e intelectuais protagonizaram, muitas vezes, o combate, sendo reconhecidos como inimigos de guerra ${ }^{11}$, cuja atuação nas disputas pelo imaginário mostrava-se inseparável de suas atividades eficientes de defesa, de imunização relativa aos discursos do poder colonial. Em meio a prisóes e outras tentativas de silenciamento de suas narrativas imunitárias, o campo literário desarquivou, iluminou e revelou a existência de "corpos alternativos", que não se harmonizavam com a lógica do desenvolvimento ocidental ditada em Portugal, assimilada no sudeste brasileiro e imposta às colônias africanas.

As narrativas literárias passam a inscrever, nos regimes de visibilidade, práticas simbólicas que enformam o cotidiano marcado pela exclusão dos valores da racionalidade e da modernidade colonial ${ }^{12}$. Neste sentido, a literatura atua como um espaço de deslocamento estratégico, que permite a captaçáo e a apreensão de imaginários que podem operar estruturas não hegemônicas de conhecimento.

11 Alguns exemplos deste protagonismo são o poeta angolano Agostinho Neto, o cabo-verdiano Amílcar Cabral, os escritores José Luandino Vieira, Luís Bernardo Howana, Jorge Amado, entre outros.

12 Nesta perspectiva, não é possível negligenciar o fato de que, no Brasil, em 1967, a publicaçáo do romance Quarup, de Antonio Callado, também revelou, na ficção, os impasses associados à criação do parque nacional do Xingu, às revoltas camponesas em meio a um contexto de violência e de um poder autoritário oficial. Poucos anos depois, o antropólogo Darcy Ribeiro publicou o romance Maíra (1976), fortalecendo uma linhagem narrativa que, de Milton Hatoum a Bernardo Carvalho, deu sequência às preocupaçóes "imunitárias" em face das racionalidades hegemônicas da modernidade. 
Referências

AMADO, Jorge. Capitães de areia. São Paulo: Martins, 1961.

CARVALHO, Ruy Duarte de. Desmedida: Luanda, São Paulo, São Francisco e volta. Lisboa: Cotovia, 2006.

CÂNDIDO, Antônio. Formação da Literatura Brasileira. São Paulo: Martins, v.2. 1964.

CLASTRES, Pierre. A sociedade contra o Estado. SP: Cosac \& Naify, 2003.

FANON, Frantz. Os condenados da terra. Rio de Janeiro: Civilização Brasileira, 1997.

FERREIRA DE CASTRO, Joaquim. A selva. Lisboa: Guimarães, 1982.

FOUCAULT, Michel. "Outros espaços”. In: Ditos e escritos. Rio de Janeiro: Forense, 2005.

GUINSBURG, Carlo. "Sinais: raízes de um paradigma indiciário”. In: Mitos, emblemas e sinais: morfologia e história. São Paulo: Companhia das Letras, 1989.

MIGNOLO, Walter. Desobediência Epistêmica: a opção descolonial e o significado da identidade em politica. Cadernos de Letras da UFF - Dossiê: Literatura, língua e identidade, Niterói, n.34, 2008, p. 287-324.

QUIJANO, Anibal. “Colonialidade do poder, eurocentrismo e América Latina”. In: Lander, Edgardo (Org.). A colonialidade do saber: eurocentrismo e ciências sociais. Perspectivas latino-americanas. Ciudad Autônoma de Buenos Aires, Argentina. Setembro 2005, p. 107-130. (Collección Sur Sur, GLACSO)

SANTOS, Boaventura de Sousa. Para além do Pensamento Abissal: Das linhas globais a uma ecologia de saberes. Revista Crítica de Ciências Sociais, v. 78, 2007, p. 3-46.

Alexandre Montaury Baptista Coutinho. Doutor em Letras (2004) pela Pontifícia Universidade Católica do Rio de Janeiro. Atua no Programa de Pós-Graduação em Literatura, Cultura e Contemporaneidade do Departamento de Letras da mesma universidade, onde desempenha a função de diretor. Bolsista de produtividade do CNPq (PQ-2) e Cientista do Nosso Estado (2018-2020) da FAPERJ.

E-mail: alexandre.montaury@gmail.com 